\title{
Hydroxychloroquine and chloroquine retinal safety concerns during COVID-19 outbreak
}

\author{
Massimo Nicolò $\cdot$ Lorenzo Ferro Desideri · Matteo Bassetti · Carlo Enrico Traverso
}

Received: 27 May 2020/Accepted: 5 September 2020/Published online: 18 September 2020

(C) The Author(s) 2020

\begin{abstract}
Purpose The current coronavirus disease 2019 (COVID-19) has been declared by the World Health Organization a global pandemic. Chloroquine (CQ) and hydroxychloroquine (HCQ) have been largely adopted in the clinical setting for the management of SARS-CoV-2 infection; however, their known retinal toxicity has raised some safety concerns, especially considering the higher-dosage employed for COVID19 patients as compared with their suggested posology for their usual indications, including systemic lupus erythematosus and other rheumatic diseases.In this review, we will discuss the optimal dosages recommended for COVID-19 patients when treated with HCQ and CQ.
\end{abstract}

M. Nicolò $(\varangle) \cdot$ L. Ferro Desideri · C. E. Traverso IRCCS Ospedale Policlinico San Martino, University Eye Clinic of Genoa, Genova, Italy e-mail: massimonicolo@gmail.com

M. Nicolò · L. Ferro Desideri · C. E. Traverso Department of Neurosciences, Rehabilitation, Ophthalmology, Genetics, Maternal and Child Health (DiNOGMI), University of Genoa, Genova, Italy

M. Nicolò

Macula Onlus Foundation, Genova, Italy

M. Bassetti

Infectious Diseases Clinic, Department of Health Sciences, University of Genova and Ospedale Policlinico

San Martino- IRCCS Per L'Oncologia, Genova, Italy
Methods A comprehensive literature search was performed in PubMed, Cochrane library, Embase and Scopus, by using the following search terms: "chloroquine retinal toxicity" and "hydroxychloroquine retinal toxicity" alone or in combination with "coronavirus", "COVID-19”, “ SARS-CoV-2 infection " from inception to August 2020.

Results Although there is still no consistent evidence about $\mathrm{HCQ} / \mathrm{CQ}$ retinal toxicity in patients with COVID-19, these possible drug-related retinal adverse events may represent a major safety concern. For this reason, appropriate screening strategies, including telemedicine, should be developed in the near future. Conclusion A possible future clinical perspective for patients with COVID-19 treated with HCQ/CQ could reside in the multidisciplinary collaboration between ophthalmologists monitoring the risk of HCQ/CQrelated retinal toxicity and those physicians treating COVID-19 infection.

Keywords Hydroxychloroquine - Chloroquine · Retina $\cdot$ Retinal safety $\cdot$ COVID-19 Coronavirus · SARCoV-2

\section{Introduction}

The current coronavirus disease 2019 (COVID-19) has been declared by the World Health Organization (WHO) a global pandemic in early March 2020 [1]. To 
date, no specific therapy has been identified for treating COVID-19; however, beside antiviral drugs, chloroquine (CQ) and hydroxychloroquine (HCQ) have been employed for the management of SARSCoV-2 infection [2]. In this regard, HCQ and CQ belong to the class of synthetic antimalarial drugs, which are generated from the bark of cinchona (Rubiaceae) are characterized by a water solubility (HCQ is more soluble given its hydroxyl group) and a long plasma elimination half-life $\left(t_{1 / 2}\right)$ of 1300 and 900 h, respectively [3]. Their antiviral properties are thought to reside in their capacity to increase the lysosomes, endosomes and Golgi complex $\mathrm{pH}$ due to the accumulation of aminoquinolines and therefore by making viral replication more difficult [4].

In vitro studies showed HCQ and CQ efficacy in inhibiting SARS-CoV-2 replication.

[5] [6]. To date, there are more than 20 ongoing randomized clinical trials (RCTs) on both medications for treatment of COVID-19 [7]. In particular, Gao et al. demonstrated the clinical efficacy of CQ in reducing pneumonia exacerbation and improving lung imaging findings in more than 100 patients [8]. Similarly, Gautret et al. showed that HCQ was effective in reducing viral load in 20 patients with COVID-19 [9].

Given this background, the Italian Society of Infectious and Tropical disease recommended the administration of CQ $500 \mathrm{mg} \times 2 /$ die or HCQ $200 \mathrm{mg} / \mathrm{die}$ for 10 days, with possible extension to 20 days according to the severity of the disease [10]; similarly, the Dutch Center of Disease control (CDC) suggested in adults a regimen with $600 \mathrm{mg}$ of CQ followed by $300 \mathrm{mg}$ after $12 \mathrm{~h}$ on day 1 , then $300 \mathrm{mg} \times 2$ /die per os on days 2-5 days [11]. In this review, we will analyze all the studies dealing with HCQ and CQ-related retinal toxicity, especially focusing on the setting of patients with COVID-19 infection. In particular, we will discuss the possible role of screening strategies for the early detection of HCQ/CQ-related retinal toxicity in these patients and the importance of a multidisciplinary collaboration between ophthalmologists and those doctors treating COVD-19 infection.

\section{Methods}

A literature search was performed in order to find all the published studies dealing with HCQ and CQ retinal toxicity from inception until August 2020. The following electronic databases were adopted: Medline, PubMed, Science Citation Index via Web of Science, and the Cochrane Library. The following search terms were used: "chloroquine retinal toxicity" and "hydroxychloroquine retinal toxicity " alone or in combination with "coronavirus", "covid 19", " SARS-CoV-2 infection ". Moreover, all the articles were thoroughly evaluated and their reference lists were also studied in order to find other manuscripts that could be included in this present review study.

\section{HCQ and CQ retinal toxicity}

It has been largely reported that CQ and HCQ may display a retinal toxic effect when used for a long time in patients lupus erythematosus (SLE) and other rheumatoid diseases.

The lower toxicity of HCQ compared with CQ has been referred to the presence of the hydroxyl group limiting the ability of HCQ to cross the blood-retinal barrier [12]. Preclinical studies showed that HCQ and CQ are melanotropic drugs, binding to the melanin of the retinal pigmented epithelium (EPR); however, it has not fully understood the pathogenetic mechanism, which is thought to primarily occur in the neural retina (ganglion cells and photoreceptors), with subsequent alterations in the RPE showing intracellular accumulation of lipofuscin [13]. In a recent in vitro study, HCQ and CQ were shown to block the uptake activity of an organic anion transporting polypeptide 1A2 (OATP1A2), which is expressed in human RPE cells and is involved in the recycling of all-trans-retinol. In fact, HCQ inhibited significantly the uptake of alltrans-retinol in human embryonic kidney cells (HEK293) and primary human RPE cells. This study would suggest the effect of HCQ and CQ on the visual cycle function, whose alteration may lead to vision impairment and to development of the retinopathy clinically observed [14]. From a clinical perspective, CQ and HCQ retinal toxicity is usually asymptomatic with the preservation of visual acuity in the early stages. In more advanced stages, patients may experience a decreased visual acuity and peripheral vision, alterations in night vision until the formation of a paracentral scotoma [15]. A pathognomonic clinical sign, characterized by the onset of a "bull's eye", is due the formation of a perifoveal ring of retinal 
pigment epithelium (RPE) atrophy sparing the fovea and it usually causes irreversible visual loss [12].

Interestingly, some ethnic differences have been reported, since HCQ retinopathy typically presents with a pericentral pattern (instead of the parafoveal bull's eye) in Asian patients [16].

A retrospective case-control study on 2361 patients under protracted HCQ treatment for at least 5 years reported an overall prevalence of HCQ-related retinopathy of $7.5 \%$, varying in relation to the daily dosage. In particular, with a dosage ranging from 4.0 to $5.0 \mathrm{mg} / \mathrm{kg}$, the prevalence of retinal toxicity was less than $2 \%$ within the first 10 years of treatment but increased to almost 20\% after 20 years [17]. By contrast, a larger scale study including data from the National Data Bank for Rheumatic Diseases on 3995 patients with SLE or rheumatoid arthritis (RA) treated with HCQ and found 298 patients reporting a diagnosis of HCQ-induced retinopathy. After multiple imputation for missing data, the authors revealed an overall risk of retinopathy of $0.65 \%$, in particular $1.0 \%$ after 10 years of treatment and $3.1 \%$ at 20 years of use. The lower prevalence of HCQ-induced retinopathy reported in this study was probably due to the presence of missing data and the adoption of older screening modalities [18].

Moreover, other known risk factors associated with HCQ-related retinopathy are the presence of a concomitant renal disease, use of tamoxifen and other macular diseases [15].

Considering that this iatrogenic retinopathy is referred to be associated with a high dosage and long-term treatment period, the American Academy of Ophthalmology (AAO) has recommended a maximum daily dose $\leq 5.0 \mathrm{mg} / \mathrm{kg}$ real body weight for HCQ and $\leq 2.3 \mathrm{mg} / \mathrm{kg}$ real body weight for CQ [15].

Similarly, the British Royal College of Ophthalmologists (RCO) has indicated a daily dose of HCR inferior to $5 \mathrm{mg} / \mathrm{kg} / \mathrm{day}$ for less than 5 years as relatively safe for retinal toxicity [19].

According to the AAO, a retinal screening is recommended at baseline and within the first year and five years for the treatment with CQ and HCQ, respectively [15]; moreover, both AAO and RCO underlined that the retinal screening should be performed earlier if the major risk factors are present [15] [19].

The current doses proposed for treating COVID-19 are 4-5 times higher than those suggested by AAO and
$\mathrm{RCO}$ [20]. In this regard, studies investigating the role of HCQ in non-rheumatoid diseases revealed an incidence of drug-related retinopathy ranging from 25 to $40 \%$ within the year of treatment [15]. In particular, Leung et al. reported the rapid incidence of HCQ-related retinopathy in 2 out of 7 oncologic patients treated with HCQ $1000 \mathrm{mg}$ for lung cancer. Signs of retinopathy were demonstrated by spectraldomain optical coherence tomography (OCT) and multifocal electroretinography (mfERG). Although a possible synergic retinal toxic effect of HCQ with erlotinib could have not been ruled out, this study proved that high doses of HCQ may lead to retinal toxicity within 1-2 years of treatment [21].

In another cohort study, retinal toxicity was examined in 12 patients with chronic graft-versus-host disease treated with high doses of HCQ (median $11.5 \mathrm{mg} / \mathrm{kg} /$ day $) .25 \%$ of the patients $(\mathrm{n}=3 / 12)$ showed retinal toxicity with the onset of scotomas in the Amsler grid and Humphrey 10-2 automated perimetry. Hence, also this study showed the association between higher doses of HCQ and an increased and earlier incidence of drug-related retinopathy [22].

Moreover, it is known that chronic CQ abusers are highly susceptible to retinal damage; one study on patients with heart block revealed that CQ chronic abuse was associated with the onset of CQ-related retinopathy in $53.8 \%$ of them [23]. (Table 1).

\section{Screening and diagnostic modalities}

In the last years, several both structural and functional, diagnostic techniques have been investigated for the screening of HCQ-related retinopathy [24].

Among them, the AAO guidelines (2016) recommended the combination between a functional test, the automated 10-2 VFA and a structural imaging technique, the spectral domain optical coherence tomography (SD-OCT), as a first choice to detect early signs of HCQ-induced retinopathy [25].

The earliest signs of retinopathy detected on the central visual field by 10-2 VFA are represented by a cluster of paracentral points with decreased sensitivity. With the progress of the disease, a partial bull's eye scotoma resembling an arcuate defect may appear and subsequently developing into a complete bull's eye scotoma with a full ring defect sparing the fovea [26]. 
Table 1 Recommended HCQ and CQ dosage released by the various international ophthalmological societies regarding preventing drug-induced retinal toxicity

\begin{tabular}{|c|c|c|c|c|c|}
\hline & Dutch guidelines & Belgian guidelines & Italian guidelines & $\begin{array}{l}\text { Chinese } \\
\text { guidelines }\end{array}$ & Thailandese guidelines \\
\hline $\begin{array}{l}\text { Recommeneded } \\
\text { HCQ dosage }\end{array}$ & $\begin{array}{l}800 \mathrm{mg} \text { at day } 1 \text {, } \\
\text { then } 400 \mathrm{mg} / \text { day } \\
\text { up to } 5 \text { days }\end{array}$ & $\begin{array}{l}800 \mathrm{mg} \text { at day } 1, \\
\text { then } 400 \mathrm{mg} / \text { day } \\
\text { up to } 5 \text { days }\end{array}$ & $\begin{array}{l}800 \mathrm{mg} \text { at day } 1, \text { then } \\
400 \mathrm{mg} / \text { day up to } \\
10 \text { days }\end{array}$ & N/A & $\begin{array}{l}800 \mathrm{mg} \text { at day } 1, \text { then } \\
400 \mathrm{mg} / \text { day for at } \\
\text { least } 5 \text { days }\end{array}$ \\
\hline $\begin{array}{l}\text { Recommeneded } \\
\text { CQ dosage }\end{array}$ & $\begin{array}{l}900 \mathrm{mg} \text { at day } 1 \text {, } \\
\text { then } 600 \mathrm{mg} / \text { day } \\
\text { up to } 5 \text { days }\end{array}$ & $\begin{array}{l}900 \mathrm{mg} \text { at day } 1, \\
\text { then } 600 \mathrm{mg} / \text { day } \\
\text { up to } 5 \text { days }\end{array}$ & $\begin{array}{l}1000 \mathrm{mg} / \text { day up to } \\
10 \text { days }\end{array}$ & $\begin{array}{l}1000 \mathrm{mg} / \text { day } \\
\text { up to } \\
10 \text { days }\end{array}$ & $\begin{array}{l}500 / \mathrm{mg} \text { day for at least } \\
5 \text { days }\end{array}$ \\
\hline
\end{tabular}

CQ-Chloroquine; HCQ-Hydroxychloroquine

On the other hand, SD-OCT imaging can detect early alterations occurring in the retinal layers before the onset of a clinically visible HCQ- related retinopathy; in particular, early alterations are visualized as a disruption of the outer nuclear layer, external limiting membrane and RPE in the parafoveal area [27]. A distinctive sign of HCQ-induced retinopathy is the "flying saucer sign", which is caused by the preservation of the central subfoveal architecture at the detriment of the atrophy of the contiguous perifoveal outer retinal tissue [28].

While SD-OCT has been proven to be objective and highly specific, by contrast, the 10-2 VFA examination is a subjective tool and it has been revealed to be more sensitive than SD-OCT in detecting the earliest HCQ-induced alterations occurring in retinal layers [25].

In this regard, a retrospective study on 121 patients taking HCQ or CQ showed that SD-OCT alone had a sensitivity of $78.6 \%$ and a specificity of $98.1 \%$, while for 10-2 VFA were $85.7 \%$ and $92.5 \%$, respectively. Moreover, the combination between 10 and 2 VFA and SD-OCT examinations improved the overall sensitivity and specificity to $85.7 \%$ and $92.5 \%$, respectively [29].

In addition, multifocal electroretinography (mfERG) has been revealed to be a very sensitive screening test to detect early alterations in HCQrelated retinopathy, in particular by showing the paracentral reductions in amplitude, which are considered to be the most specific waveform pattern of this iatrogenic retinopathy; however, considering the cost, the limited access, the need of a well-trained technician staff and the importance of patient's collaboration, mfERG should not be considered as a first choice screening modality [30].

Fundus autofluorescence (FAF) is an in vivo imaging technique, detecting the distribution of lipofuscin in the outer retina, subretinal space and RPE. In patients treated with HCQ, FAF may detect an augmented signal intensity due to the altered distribution secondary to the early damage in the photoreceptor layer. Similarly to mfERG, given its operatordependent nature, FAF should be considered more a complementary screening test rather than a primary choice [31].

Fundus photography can be considered a helpful descriptive tool in advanced stages of the disease, because visible HCQ-related retinopathy is often a late clinical finding. Thus, the AAO did not recommend fundus photography as a first choice for screening HCQ-induced retinopathy [26].

Lastly, other diagnostic modalities such as color vision assessments, Amsler grid, fluorescein angiography (FA) and electro-oculography are not currently recommended as primary screening examinations, since they have not been proven to be sufficiently sensitive for detecting HCQ-related retinopathy [32].

Clinical perspectives during covid-19 outbreak

To date, it has not been demonstrated if the HCQ or CQ exposure at higher doses over a short treatment period is likewise associated with comparable retinal toxicity as with the chronic exposure. In addition, other main concerns raised by the EU Eye for the management of COVID-19 patients with HCQ and CQ are the presence of a polypharmacy and the 
combination between high doses and a high comorbidity, respectively [33].

The main issues are represented by the risk of overdosing HCQ and CQ in COVID-19 because of the relatively low awareness among doctors about this iatrogenic toxicity, in combination with the lack of evidence about a fixed regimen of these drugs adopted in COVID-19 patients, and, nonetheless, the faster deterioration in COVID-19 patients under mechanical ventilation, which has been reported to reduce muscle mass by $2.4 \%$ per day, leading to the increase of skeletal muscle creatinine kinase levels [34]. In this regard, pharmacokinetic studies have demonstrated the large volume of distribution $\left(\mathrm{V}_{\mathrm{d}}\right)$ of HCQ, which is distributed across a variety of tissues, including fatty tissues [35]; for this reason, there is still a debate about the optimal HCQ dosing regimen in relation to the weight measurements used in these calculations, and in particular between the ideal body weight (IBW) and the adjusted body weight (ABW) [36].

Furthermore, as suggested by the Belgian guidelines for COVID-19 management, those patients with a medical history of maculopathy or other retinal diseases should be screened before HCQ/CQ treatment, in order not to neglect an important contraindication possibly causing toxic retinopathy [37].

Currently, there is still no general consensus about the optimal dosage and duration of the treatment with HCQ/CQ for COVID-19 patients, doses are generally higher than those recommended for systemic diseases and there are no homogenous guidelines on the possibility to recontrol and module the dosage during the treatment. In this regard, the current clinical trials on HCQ/CQ should carefully consider the possibility of seasonal recurrences of SARS-CoV-2 infection, which would lead to the adoption of $\mathrm{HCQ} / \mathrm{CQ}$ cumulative doses and therefore a higher risk of retinal toxicity.

We recognize that a traditional on site ophthalmologic visit, usually considered mandatory, could not be realistic in hospitalized patients with COVID-19 needing a primary support and often mechanical ventilation.

However, trying to transform the COVID-19 problem in an opportunity, we should rethink HCQ or CQ retinal screening visit also to be feasible in hospitalized COVID-19 patients or after recovery. Currently, OCT reporting the ganglion cell complex (GCL), retinal nerve fiber layer (RNFL) and other retinal layers thicknesses and 10-2 VFA examinations as primary screening tests, in combination with other additional imaging modalities (FAF and fundus photography), can be easily performed by trained technicians like nurses working in COVID-19 division, who can acquire electronic retinal images to be evaluated remotely afterward by an ophthalmologist trained in retinal disease.

In this regard, in the last years the concept of telemedicine has been rapidly growing in the ophthalmological field, in order to facilitate the evaluation, diagnosis, and management of remote patients [38]. For example, the SUNDROP Study, a retrospective analysis in more than 1000 premature newborns, revealed that telemedicine had a sensitivity of $100 \%$ and specificity of $99.8 \%$ for screening the retinopathy of prematurity (ROP) [39]. Moreover, given the high percentage of diabetic patients unaware of their diabetic retinopathy (almost $70 \%$ of them), many screening programs have been investigated in terms of the cost-effectiveness and reliability of telemedicine for this disease, showing promising results in this respect [40]. In this way, fundus photographs and OCT examinations are taken by nursing staff or technicians and forwarded to a remote reading center, where the ophthalmologist can make the diagnosis and write a medical report for the follow-up and further clinical evaluation of the patient [41].

Interestingly, the role of telemedicine is being studied with encouraging results also for the screening of other common ocular diseases, including agerelated macular degeneration and glaucoma [42] [43].

Hence, given this evidence and the increasing adoption in the clinical practice of HCQ for treating COVD-19, in the near future, further clinical studies should better investigate the role of telemedicine for the screening of HCQ-related retinopathy. This scenario would lead to the necessity to establish a multidisciplinary collaboration between ophthalmologists and those physicians providing the primary care for COVID-19.

\section{Conclusion}

Although there is still no consistent evidence about the clinical efficacy of HCQ and CQ for treating COVID19 , these 2 drugs have been largely employed in the clinical setting; moreover, several, new clinical trials 
are investigating the role of HCQ and CQ for the treatment of COVID-19 patients. Given this background, it is likely that HCQ and CQ retinal toxicity could represent a non-negligible issue in the near future. In this regard, further larger-scale clinical studies should provide a more detailed evidence of the HCQ/CQ-related retinal toxicity in COVID-19 patients, in order to better address their clinical management from an ophthalmological perspective. Given the critical issue and possible contagiousness, COVID-19 division should be equipped with the necessary instruments need to screen retinal features for possible HCQ or CQ toxicity diagnosed remotely. The multidisciplinary collaboration between eye doctors and those physicians treating COVID-19 infection will probably represent an important issue to handle in the near future.

Funding Open access funding provided by Università degli Studi di Genova within the CRUI-CARE Agreement. The authors received no financial support for the research, authorship, and/or publication of this article.

\section{Compliance with ethical standards}

Conflict of interest The authors declare that they have no conflicts of interest.

Consent for publication The authors confirm that the statement of consent to publish this case and these images was gathered from the patient.

Open Access This article is licensed under a Creative Commons Attribution 4.0 International License, which permits use, sharing, adaptation, distribution and reproduction in any medium or format, as long as you give appropriate credit to the original author(s) and the source, provide a link to the Creative Commons licence, and indicate if changes were made. The images or other third party material in this article are included in the article's Creative Commons licence, unless indicated otherwise in a credit line to the material. If material is not included in the article's Creative Commons licence and your intended use is not permitted by statutory regulation or exceeds the permitted use, you will need to obtain permission directly from the copyright holder. To view a copy of this licence, visit http://creativecommons.org/licenses/by/4.0/.

\section{References}

1. Cucinotta D, Vanelli M (2020) WHO declares COVID-19 a pandemic. Acta Biomed 91(1):157-160

2. Zhou D, Dai SM, Tong Q (2020) COVID-19: a recommendation to examine the effect of hydroxychloroquine in preventing infection and progression. J Antimicrob Chemother 75:1667-1670. https://doi.org/10.1093/jac/dkaa114

3. Kalia S, Dutz JP (2007) New concepts in antimalarial use and mode of action in dermatology. DermatolTher 20(4):160-174

4. Plantone D, Koudriavtseva T (2018) Current and future use of chloroquine and hydroxychloroquine in infectious, immune, neoplastic, and neurological diseases: a mini-review. Clin Drug Investig 38(8):653-671

5. Wang M, Cao R, Zhang L, Yang X, Liu J, Xu M et al (2020) Remdesivir and chloroquine effectively inhibit the recently emerged novel coronavirus (2019-nCoV) in vitro. Cell Res 30(3):269-271

6. Yao X, Ye F, Zhang M, Cui C, Huang B, Niu P et al (2020) In vitro antiviral activity and projection of optimized dosing design of hydroxychloroquine for the treatment of severe acute respiratory syndrome coronavirus 2 (SARS-CoV-2). Clin Infect Dis 71:732-739. https://doi.org/10.1093/cid/ ciaa237

7. Sinha N, Balayla G (2020) Hydroxychloroquine and covid19. Postgrad Med J 96(1139):550-555. https://doi.org/10. 1136/postgradmedj-2020-137785

8. Gao J, Tian Z, Yang X (2020) Breakthrough: chloroquine phosphate has shown apparent efficacy in treatment of COVID-19 associated pneumonia in clinical studies. Biosci Trends 14(1):72-73

9. Gautret P, Lagier JC, Parola P, Hoang VT, Meddeb L, Mailhe $M$ et al (2020) Hydroxychloroquine and azithromycin as a treatment of COVID-19: results of an openlabel non-randomized clinical trial. Int J Antimicrob Agents 56:105949

10. Italian Society of Infectious and Tropical disease Guidelines 2020. https://www.simit.org/medias/1555-covid19-lineeguida-trattamento-01mar.pdf

11. Dutch Center of Disease control guidelines 2020. https://lci. rivm.nl/covid-19/bijlage/behandeladvies

12. Raines MF, Bhargava SK, Rosen ES (1989) The bloodretinal barrier in chloroquine retinopathy. Invest Ophthalmol Vis Sci 30(8):1726-1731

13. Rosenthal AR, Kolb H, Bergsma D, Huxsoll D, Hopkins JL (1978) Chloroquine retinopathy in the rhesus monkey. Invest Ophthalmol Vis Sci 17(12):1158-1175

14. Xu C, Zhu L, Chan T, Lu X, Shen W, Madigan MC et al (2016) Chloroquine and hydroxychloroquine are novel inhibitors of human organic anion transporting polypeptide 1A2. J Pharm Sci 105(2):884-890

15. Marmor MF, Kellner U, Lai TY, Melles RB, Mieler WF (2016) Recommendations on Screening for Chloroquine and Hydroxychloroquine Retinopathy (2016 Revision). Ophthalmology 123(6):1386-1394

16. Melles RB, Marmor MF (2015) Pericentral retinopathy and racial differences in hydroxychloroquine toxicity. Ophthalmology 122(1):110-116

17. Melles RB, Marmor MF (2014) The risk of toxic retinopathy in patients on long-term hydroxychloroquine therapy. JAMA Ophthalmol 132(12):1453-1460

18. Wolfe F, Marmor MF (2010) Rates and predictors of hydroxychloroquine retinal toxicity in patients with rheumatoid arthritis and systemic lupus erythematosus. Arthritis Care Res (Hoboken) 62(6):775-784 
19. Yusuf IH, Foot B, Galloway J, Ardern-Jones MR, Watson SL, Yelf C et al (2018) The Royal College of Ophthalmologists recommendations on screening for hydroxychloroquine and chloroquine users in the United Kingdom: executive summary. Eye (Lond) 32(7):1168-1173

20. Ruamviboonsuk P, Lai TYY, Chang A, Lai CC, Mieler WF, Lam DSC et al (2020) Chloroquine and hydroxychloroquine retinal toxicity consideration in the treatment of COVID-19. Asia Pac J Ophthalmol (Phila) 9(2):85-87

21. Leung LS, Neal JW, Wakelee HA, Sequist LV, Marmor MF (2015) Rapid onset of retinal toxicity from high-dose hydroxychloroquine given for cancer therapy. Am J Ophthalmol 160(4):799-805.e1

22. Navajas EV, Krema H, Hammoudi DS, Lipton JH, Simpson ER, Boyd S et al (2015) Retinal toxicity of high-dose hydroxychloroquine in patients with chronic graft-versushost disease. Can J Ophthalmol 50(6):442-450

23. Magulike NO, Ihenacho HN, Ike VO (1993) Chloroquine retinopathy in Nigerian patients with heart block. Eye (Lond) 7(Pt 4):591-593

24. Pandya HK, Robinson M, Mandal N, Shah VA (2015) Hydroxychloroquine retinopathy: a review of imaging. Indian J Ophthalmol 63(7):570-574

25. Melles RB, Marmor MF (2016) The Prevalence of Hydroxychloroquine Retinopathy and Toxic Dosing, and the Role of the Ophthalmologist in Reducing Both. Am J Ophthalmol 170:240

26. Marmor MF (2012) Comparison of screening procedures in hydroxychloroquine toxicity. Arch Ophthalmol 130(4):461-469

27. Rodriguez-Padilla JA, Hedges TR 3rd, Monson B, Srinivasan V, Wojtkowski M, Reichel E et al (2007) High-speed ultra-high-resolution optical coherence tomography findings in hydroxychloroquine retinopathy. Arch Ophthalmol 125(6):775-780

28. Chen E, Brown DM, Benz MS, Fish RH, Wong TP, Kim RY et al (2010) Spectral domain optical coherence tomography as an effective screening test for hydroxychloroquine retinopathy (the "flying saucer" sign). ClinOphthalmol 4:1151-1158

29. Browning DJ, Lee C (2014) Relative sensitivity and specificity of 10-2 visual fields, multifocal electroretinography, and spectral domain optical coherence tomography in detecting hydroxychloroquine and chloroquine retinopathy. ClinOphthalmol 8:1389-1399

30. Penrose PJ, Tzekov RT, Sutter EE, Fu AD, Allen AW Jr, Fung WE et al (2003) Multifocal electroretinography evaluation for early detection of retinal dysfunction in patients taking hydroxychloroquine. Retina 23(4):503-512

31. Marmor MF (2013) Fundus autofluorescence is not the best early screen for hydroxychloroquine toxicity. JAMA Ophthalmol 131(11):1487-1488
32. Jorge A, Ung C, Young LH, Melles RB, Choi HK (2018) Hydroxychloroquine retinopathy-implications of research advances for rheumatology care. Nat Rev Rheumatol 14(12):693-703

33. Eye E. Hydroxychloroquine and chloroquine use for Covid19. 2020.

34. Barazzoni R, Bischoff SC, Breda J, Wickramasinghe K, Krznaric Z, Nitzan D et al (2020) ESPEN expert statements and practical guidance for nutritional management of individuals with SARS-CoV-2 infection. ClinNutr 39(6):1631-1638. https://doi.org/10.1016/j.clnu.2020.03. 022

35. Titus EO (1989) Recent developments in the understanding of the pharmacokinetics and mechanism of action of chloroquine. Ther Drug Monit 11(4):369-379

36. Marmor MF (2017) Hydroxychloroquine Screening Alert: Change is in the Wind. Ophthalmic Surg Lasers Imaging Retina 48(2):96-98

37. Institute of Tropical Medicine Antewerp, UniversiteitAntwerpen, CHU Saint-Pierre, et al. Interim Clinical Guidance for Patients Suspected of/Confirmed With Covid-19 in Belgium. 2020: 1-13. Available at: https://epidemio.wivisp.be/ID/Documents/Covid19/COVID-19_ InterimGuidelines_Treatment_ENG.pdf. Accessed 23 Mar 2020.

38. Rathi S, Tsui E, Mehta N, Zahid S, Schuman JS (2017) The Current State of Teleophthalmology in the United States. Ophthalmology 124(12):1729-1734

39. Wang SK, Callaway NF, Wallenstein MB, Henderson MT, Leng T, Moshfeghi DM (2015) SUNDROP: six years of screening for retinopathy of prematurity with telemedicine. Can J Ophthalmol 50(2):101-106

40. Zimmer-Galler IE, Kimura AE, Gupta S (2015) Diabetic retinopathy screening and the use of telemedicine. CurrOpinOphthalmol 26(3):167-172

41. Kirkizlar E, Serban N, Sisson JA, Swann JL, Barnes CS, Williams MD (2013) Evaluation of telemedicine for screening of diabetic retinopathy in the Veterans Health Administration. Ophthalmology 120(12):2604-2610

42. Group AHSR, Chew EY, Clemons TE, Bressler SB, Elman MJ, Danis RP et al (2014) Randomized trial of a home monitoring system for early detection of choroidal neovascularization home monitoring of the Eye (HOME) study. Ophthalmology 121(2):535-44

43. Thomas S, Hodge W, Malvankar-Mehta M (2015) The Cost-Effectiveness Analysis of Teleglaucoma Screening Device. PLoS ONE 10(9):e0137913

Publisher's Note Springer Nature remains neutral with regard to jurisdictional claims in published maps and institutional affiliations. 